\title{
ĐIỀU TRA VÀ ĐÚC KẾT TRI THỨC CỦA CộNG ĐỒNG DÂN TỘC THIỂU SỐ TỈNH LAI CHÂU TRONG ÚNG PHÓ VỚI THIÊN TAI VÀ KHÍ HẬU CỰC ĐOAN
}

\begin{abstract}
Vũ Văn Cương ${ }^{1}$, Trần Thục ${ }^{2}$, Đinh Thái Hưng ${ }^{3}$
Tóm tắt: Hệ thống tri thức của cộng đồng dân tộc thiểu số tỉnh Lai Châu đã được tích lũy qua hàng nghìn năm trong quá trình lao động sản xuất. Nhũng tri thức này, chứa đựng nhiều kinh nghiệm, kỹ thuật thực hành và ứng xử với môi truờng tụ nhiên, đã giúp nguời dân giảm nhẹ tác động của thiên tai và khi hậu cưc đoan trong trồng trọt, chăn nuôi và quản lý tài nguyên thiên nhiên. Bài báo này trình bày kết quả đánh giá tri thức của cộng đồng dân tộc thiểu số tỉnh Lai Châu trong úng phó với thiên tai và khí hậu cực đoan trong các lĩnh vực kinh tế - xã hội. Phurong pháp Delphi được áp dụng trong điều tra xã hội học ở cộng đồng người Dao tại xã Hồ Thầu, người H'Mông ở xã Tà Lèng, người Hà Nhì ở xã Thu Lũm huyện Mường Tè đại diện vùng sinh thái đai cao tù $500 m$ đến trên 1500m; cộng đồng ngườ Lào ở Nà Tăm huyện Tam Đuờng, người Thái ở Tân Uyên đại diện cho vùng sinh thái đai thấp tì̀ $500 \mathrm{~m}$ trở xuống. Nhũng tri thức quý giá của cộng đồng dân tộc thiểu số ở Lai Châu được phân tích và đúc kết trong nghiên cứu này bao gồm: về nhà ở; phương thức sử dụng giống cây địa phưong trong sản xuất lương thực, thực phẩm; kỹ thuật canh tác xen canh, luân canh cây trồng trên nương, trên ruộng một vu lúa; phương thức chuyển đổi cây trồng trên nương; các kỹ thuật trong chăn nuôi gia súc và quản lý nguồn nuớc, tài nguyên rùng bằng luật tục, tín ngữ̃ng.
\end{abstract}

Từ khóa: Tri thức của cộng đồng, dân tộc thiểu số, úng phó thiên tai và khi hậu cực đoan.

Ban Biên tập nhận bài: 18/10/2018 Ngày phản biện xong: 05/12/2018 Ngày đăng bài: 25/01/2019

\section{1. Đặt vấn đề}

Lịch sử tồn tại, phát triển của cộng đồng các dân tộc thiểu số cho thấy người dân đã tự thuần hoá các giống cây lương thực, thực phẩm từ tự nhiên, cải tạo đất tự nhiên thành đất sản xuất, điều chỉnh các hành vi để tạo ra kỹ thuật trồng, chăm sóc và thu hoạch cây trồng theo mùa vụ, thiết lập các nguyên tắc ứng xử giữa con người với tự nhiên theo hướng quản lý, khai thác bền vững nguồn tài nguyên thiên nhiên. Do đó, hệ thống tri thức của cộng đồng trong quản lý xã hội, sản xuất và ứng xử với thiên nhiên đã trở thành nền tảng, cơ sở giúp cộng đồng các dân tộc thiểu số giải quyết vấn đề lương thực, quản lý tài nguyên [2][8]. Trong hoạt động thích ứng và

${ }^{1}$ Sỏ Khoa họ và Công nghệ tỉnh Lai Châu ${ }^{2}$ Viện Khoa học Khi tương Thủy văn và Biến đổi khì hậu

${ }^{3}$ Tổng Cuc Khí tương Thủy văn

Email:vucuongkhcnlc@gmail.com giảm thiểu những thiệt hại do khí hậu cực đoan và thiên tai gây ra, người dân đã sử dụng nhiều giải pháp phong phú như: sử dụng các giống lúa, giống mạch sinh trưởng ngắn ngày, chống chịu khô hạn và trồng xen nhiều loại cây trên cùng một diện tích canh tác (trồng xen cây mạch, đậu tương, khoai tây). Khi môi trường khí hậu thay đổi, tri thức của cộng đồng trở thành cơ sở quý giá cho việc phát triển các chiến lược thích ứng và quản lý tài nguyên thiên nhiên ở cấp địa phương [7]. Bài báo này trình bày kết quả điều tra và đúc kết những giải pháp, tri thức cộng đồng đã và đang được áp dụng ứng phó hiệu quả với thiên tai và khí hậu cực đoan trên địa bàn tỉnh Lai Châu.

\section{2. Địa bàn và phương pháp nghiên cứu}

- Địa bàn nghiên cứu: Tỉnh Lai Châu là tỉnh miền núi, diện tích đất tự nhiên có trên $60 \%$ ở độ cao trên $1000 \mathrm{~m}$, hơn $90 \%$ diện tích có độ dốc trên 250 , đất nông nghiệp chiếm $92 \%$ diện tích 
đất tự nhiên [5]. Lai Châu có 20 cộng đồng dân tộc thiểu số cùng sinh sống, cư trú ở các vùng sinh thái khác nhau. Vùng sinh thái có độ cao từ 900 đến $1500 \mathrm{~m}$ là nơi cư trú các dân tộc H'Mông, Dao và Hà Nhì; vùng sinh thái có độ cao từ 500-900m là nơi cư trú của dân tộc Dao và Hà Nhì, vùng sinh thái ven sông suối, thung lũng có độ cao dưới $500 \mathrm{~m}$ là nơi cư trú của các dân tộc Thái, Tày, Giáy, Lào và Lự [3]. Theo thống kê từ năm 2009-2016 lũ ống, lũ quét, trượt lở đất, đá, khô hạn, giông lốc và mưa đá đã làm 5023ha lúa, hoa màu bị mất trắng, 189 công trình thủy lợi, nước sinh hoạt và $15,4 \mathrm{~km}$ bờ kênh thủy lợi bị lũ phá hủy. Trong 7 năm thiên tai và cực đoan khí hậu đã làm 88 người chết và bị thương, làm sập và hư hỏng 12.112 ngôi nhà [1]. Những thiệt hại về tính mạng, kinh tế - xã hội nêu trên phản ánh mức độ dễ bị tổn thương của cộng đồng các dân tộc thiểu số tỉnh Lai Châu trong hiện tại, trong tương lai những thiệt hại này có nguy cơ gia tăng dưới tác động của biến đổi khí hậu làm gia tăng tần xuất, cường độ và phạm vi tác động của thiên tai và cực đoan khí hậu.

- Phuoong pháp nghiên cúu: Điều tra xã hội bằng phương pháp Delphi được áp dụng, đây là phương pháp tham vấn để đạt được sự đồng thuận của một nhóm chuyên gia, quá trình tham vấn được lặp đi lặp lại nhiều vòng để thu thập, sàng lọc các giải pháp đề xuất của chuyên gia để đưa ra giải pháp tốt nhất [6]. Phương pháp Delphi hai vòng được áp dụng trong nghiên cứu này.

Vòng 1 là những câu hỏi mở, người tham gia khảo sát tự do đưa ra các giải pháp mà cộng đồng các dân tộc đã sử dụng để ứng phó thiên tai và khí hậu cực đoan trong trồng trọt, chăn nuôi, quản lý nguồn nước, tài nguyên rừng và bảo vệ sức khỏe nhân dân trên địa bàn tỉnh Lai Châu.

Vòng 2 là những câu hỏi đóng. Những câu trả lời của người tham gia khảo sát ở vòng 1 được tổng hợp thành các câu hỏi đóng. Bảng câu hỏi ở Vòng 2 được sắp xếp theo thang điểm từ 1 đến 5 (1 = rất không đồng ý/không tác động, 2 = không đồng ý/ít tác động, $3=$ đồng ý/tác động vừa, 4 = rất đồng ý/tác động mạnh, $5=$ hoàn toàn đồng ý/tác động nghiêm trọng). Số liệu khảo sát được xử lý trên phần mềm thống kê SPSS. Các giải pháp có giá trị trung bình lớn tiệm cận đến điểm 5 phản ánh giải pháp nhận được sự đồng thuận cao.

Hệ số Kendall $(\mathrm{W})$ được sử dụng để đánh giá mức độ đồng thuận: $W=12 \mathrm{~S} / \mathrm{m}^{2} *\left(\mathrm{n}^{3}-\mathrm{n}\right)$. Trong đó $\mathrm{S}$ là tổng độ lệch chuẩn bình phương; $\mathrm{m}, \mathrm{n}$ là số phần tử tương ứng của đối tượng $\mathrm{x}$ và $\mathrm{y}$. Giá trị của $\mathrm{W}$ đạt được theo các ngưỡng $0.0-0.1 ; 0.1$ $0.3 ; 0.3-0.5 ; 0.5-0.7 ; 0.7-1.0$ tương ứng với mức độ đồng thuận rất yếu, yếu, trung bình; mạnh, rất mạnh.

Nghiên cứu đã khảo sát tại cộng đồng các dân tộc cư trú ở vùng sinh thái khác nhau, cụ thể: Cộng đồng người Dao tại xã Hồ Thầu, người H'Mông ở xã Tà Lèng, người Hà Nhì ở xã Thu Lũm huyện Mường Tè đại diện vùng sinh thái đai cao từ $500 \mathrm{~m}$ đến trên $1500 \mathrm{~m}$; cộng đồng người Lào ở Nà Tăm huyện Tam Đường, người Thái ở Tân Uyên đại diện cho vùng sinh thái đai thấp từ $500 \mathrm{~m}$ trở xuống.

Số lượng chuyện gia được tham vấn, trong phương pháp Delphi không có nguyên tắc cố định quyết định số lượng chuyên gia, tuỳ thuộc từng nghiên cứu và số lượng chuyên gia chuyên sâu trong lĩnh vực nghiên cứu [6]. Nghiên cứu nhận thức về biến đổi khí hậu của học sinh phổ thông, Trần Minh Ngọc thực hiện điều tra 56 phiếu; Chu Thanh Hương tham vấn 60 chuyên gia trong nghiên cứu giái pháp thích ứng với BĐKH ở Quảng Ngãi. Trong nghiên cứu chúng tôi tham vấn 60 thành viên ( 60 phiếu) là những trưởng bản, người uy tín trong cộng đồng, người đang giữ chức vụ quản lý (gọi là thành viên tham gia khảo sát). Cụ thể là 40 thành viên tại 5 xã cộng đồng người Dao, H'Mông, Hà Nhì, Thái, Lào, mỗi một xã 8 thành viên; 20 thành viên là cán bộ tại các Phòng Tài nguyên và Môi trường và Phòng Nông nghiệp và Phát triển nông thôn.

\section{Kết quả nghiên cứu}

Kết quả điều tra và phân tích bao gồm: (i) Thiên tai, khí hậu cực đoan ở Lai Châu; (ii) Hệ thống tri thức của cộng đồng dân tộc thiểu số tỉnh Lai Châu trong ứng phó với thiên tai và khí hậu cực đoan. 
3.1. Thiên tai, cụcc đoan khí hậu ở Lai Châu

Kết quả khảo sát, điều tra và đánh giá phạm vị và lĩnh vực chịu tác động của thiên tai và cực đoan khí hậu ở cộng đồng dân tộc thiểu số ở Lai Châu được tổng hợp trong hình Hình 1, thể hiện như sau: thường xuất hiện ở Lai Châu bao gồm: giông lốc, mưa đá, lũ ống, lũ quét, trượt lở đất đá, khô hạn, rét đậm, rét hại.

Lĩnh vực chịu tác động lớn nhất gồm: tính mạng và tài sản của người dân, trồng trọt, chăn nuôi, nguồn nước, tài nguyên rừng.

Các loại hình thiên tai và khí hậu cực đoan

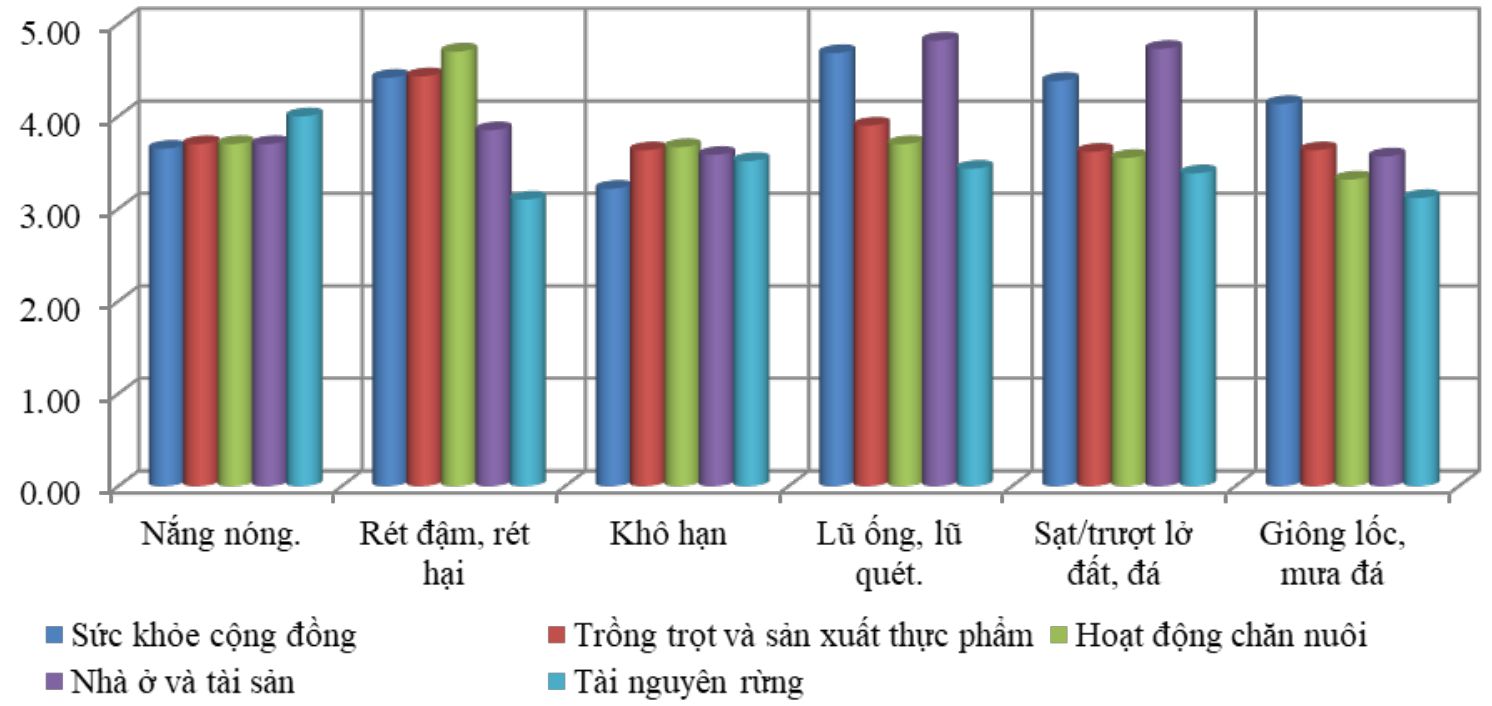

Hình 1. Tác động của thiên tai đến cộng đồng dân tộc thiểu số ở Lai Châu

3.2. Tri thức của cộng đồng đã sử dụng ứng phó thiên tai, khí hậu cụcc đoan

Trong khảo sát vòng 1 về hệ thống tri thức của cộng đồng ứng phó với thiên tai và khí hậu cực đoan trong lĩnh vực trồng trọt, chăn nuôi, quản lý khai thác nguồn nước và tài nguyên rừng, bảo vệ sức khỏe cộng đồng, chúng tôi đưa ra 5 câu hỏi mở gửi đến các thành viên tham gia khảo sát. Các thành viên chủ động đưa ra các giải pháp đã được người dân sử dụng tại cộng đồng nhằm ứng phó giảm thiểu rủi ro thiên tai và khí hậu cực đoan. Kết quả trong 5 lĩnh vực khảo sát, các thành viên đã đưa 21 giải pháp ứng phó với thiên tai được tổng hợp trong (Bảng 1), cụ thể sau:

- Tri thức của cộng đồng trong trồng trọt: Quá trình tham vấn về giải pháp ứng phó với thiên tai khô hạn, rét đậm rét hại trong khu vực, chúng tôi đã nhận được 6 giải pháp với tỷ lệ lựa chọn khác nhau. Giải pháp điều chỉnh thời vụ, sử dụng cây trồng ngắn ngày có tỷ lệ lựa chọn khá thấp lần lượt là $48 \%$ và $41 \%$; các giải pháp nhận được sự lựa chọn với tỷ lệ cao, gồm: sử dụng cây trồng địa phương $(85 \%)$, trồng chè thay thế cây màu trên nương (93\%), trồng xen canh một số loại rau với nương ngô (78\%) và trồng lạc, ngô luân canh với đất ruộng một vụ (76\%). Các giải pháp mà các thành viên đánh giá với tỷ lệ cao, là các giải pháp gắn liền với tập quán sản xuất nhỏ lẻ, kết hợp mô hình sản xuất tự cung tự cấp của người dân trong cộng đồng.

- Tri thức của cộng đồng trong chăn nuôi: Trong cộng đồng vẫn tồn tại tập quán chăn nuôi thả rông, nguồn thức ăn hoàn toàn phụ thuộc vào tự nhiên, có mức độ rủi ro cao trước thiên tai và khí hậu cực đoan. Điều này thúc đẩy người dân điều chỉnh để giảm thiểu rui ro cho đàn gia súc. Các thành viên tham gia khảo sát đã đưa ra 5 giải pháp, trong đó các giải pháp về nuôi nhốt, di chuyển đàn gia súc đi nơi khác ít được người dân sử dụng cho nên tỷ lệ lựa chọn thấp, lần lượt là $45 \%$ và $58 \%$. Các giải pháp đươc lựa chọn với tỷ lệ cao trên $70 \%$ là nuôi nhốt kết hợp với thả rông, sử dụng phụ phẩm nông nghiệp và trồng cỏ làm thức ăn dự trữ cho gia súc trong mùa đông.

- Tri thức của cộng đồng trong quản lý nguồn nước: Các thành viên đã đưa ra 3 giải pháp khai 
thác bền vững nguồn nước cho sinh hoạt, sản xuất tại cộng đồng, trong đó giải pháp phân phối, chia sẻ nguồn nước theo luật tục của cộng đồng được đánh giá thấp nhất (55\%); các giải pháp bảo vệ rừng đầu nguồn, quản lý hệ thống thủy lợi bằng luật tục là những giải pháp nhận được tỷ lệ lựa chọn cao (trên 80\%).

- Tri thức của cộng đồng trong quản lý tài nguyên rừng: Các thành viên đã đưa ra 3 giải pháp, trong đó giải pháp quản lý rừng bằng luật pháp nhận được tỷ lệ thấp nhất $(55 \%)$, hai giải pháp quản lý rừng bằng tín ngưỡng và luật tục có tỷ cao nhất (92\%); trồng cây dược liệu và cây thực phẩm dưới tán rừng có tỷ lệ lựa chọn ở mức trung bình $(77 \%)$.

- Tri thức của cộng đồng trong bảo vệ tính mạng và tài sản người dân: Có 4 giải pháp được lựa chọn, trong đó giải pháp dữ trữ lương thực, thực phẩm vào mùa mưa và hạn chế ngủ nương trong mùa mưa có tỷ lệ lựa chọn thấp nhất lần lượt là $41 \%$ và $58 \%$.

Bảng 1. Kết quả khảo sát tại vòng 1 về hệ thông tri thức của cộng đồng ứng phó với thiên tai và khí hậu cưu đoan

\begin{tabular}{|c|c|c|c|c|}
\hline $\begin{array}{l}\text { Tri thức } \\
\text { cộng } \\
\text { dồng }\end{array}$ & $\begin{array}{c}\text { Ký } \\
\text { hiệu }\end{array}$ & $\begin{array}{l}\text { Hệ thống tri thức của cộng đồng dân tộc thiểu số ứng phó với } \\
\text { thiên tai và khí hậu cực đoan ở khu vực }\end{array}$ & $\begin{array}{c}\text { Số phiếu } \\
\text { lựa chọn } \\
(\mathbf{N}=60)\end{array}$ & $\begin{array}{l}\text { Tỷ lệ } \\
\text { chọn } \\
\text { lựa } \\
(\%)\end{array}$ \\
\hline \multirow{5}{*}{$\begin{array}{c}\text { Bảo vệ } \\
\text { tính } \\
\text { mạng và } \\
\text { tài sản }\end{array}$} & S1 & Duy trì nhà ở truyền thống. & $53 / 60$ & 88 \\
\hline & $\mathrm{S} 2$ & Gia cố nhà ở trước mùa mưa. & $47 / 60$ & 80 \\
\hline & S3 & Hạn chế ngủ nương vào mùa mưa. & $35 / 60$ & 58 \\
\hline & S4 & Dự trữ lương thực, thực phẩm trong mùa mưa. & $25 / 60$ & 41 \\
\hline & $\mathrm{T} 1$ & Điều chỉnh thời vụ trồng, chăm sóc và thu hoạch cây trồng. & $29 / 60$ & 48 \\
\hline \multirow{6}{*}{$\begin{array}{c}\text { Lĩnh vực } \\
\text { trồng } \\
\text { trọt }\end{array}$} & $\mathrm{T} 2$ & Trồng cây lương thực, thực phẩm địa phương có giá trị. & $51 / 60$ & 85 \\
\hline & $\mathrm{T} 3$ & Trồng chè thay thế cây màu trên đất nương. & $56 / 60$ & 93 \\
\hline & $\mathrm{T} 4$ & Xen canh rau bí, rau đậu, dưa mèo với nương ngô. & $47 / 60$ & 78 \\
\hline & T5 & Trồng lạc, ngô luân canh trên đất sản xuất một vụ lúa. & $46 / 60$ & 76 \\
\hline & T6 & Sử dụng cây trồng ngắn ngày. & $25 / 60$ & 41 \\
\hline & $\mathrm{C} 1$ & Chăn nuôi gia súc bằng nuôi nhốt. & $27 / 60$ & 45 \\
\hline \multirow{4}{*}{$\begin{array}{l}\text { Lĩnh vực } \\
\text { chăn } \\
\text { nuôii }\end{array}$} & $\mathrm{C} 2$ & Sử dụng phụ phẩm nông nghiệp làm thức ăn dự trữ cho gia súc. & $52 / 60$ & 87 \\
\hline & $\mathrm{C} 3$ & Trồng cỏ bổ sung nguồn thức ăn cho gia súc. & $44 / 60$ & 73 \\
\hline & $\mathrm{C} 4$ & Di chuyển gia súc khi có thiên tai, khí hậu cực đoan xảy ra. & $30 / 60$ & 58 \\
\hline & $\mathrm{C} 5$ & Thả rông kết hợp với nuôi nhốt. & $60 / 60$ & 100 \\
\hline \multirow{4}{*}{$\begin{array}{l}\text { Bảo vệ } \\
\text { nguồn } \\
\text { nước }\end{array}$} & N1 & Bảo vệ rừng đầu nguồn nước bằng luật tục. & $58 / 60$ & 97 \\
\hline & $\mathrm{N} 2$ & Quản lý hệ thống thủy lợi bằng luật tục. & $51 / 60$ & 85 \\
\hline & N3 & Phân phối, chia sẻ nguồn nước luật tục của cộng đồng. & $33 / 60$ & 55 \\
\hline & $\mathrm{R} 1$ & Trồng cây dược liệu và cây thực phẩm dưới tán rừng. & $46 / 60$ & 77 \\
\hline \multirow{2}{*}{$\begin{array}{l}\text { Bảo vệ } \\
\text { rừng }\end{array}$} & $\mathrm{R} 2$ & Quản lý rừng bằng tín ngưỡng và luật tục cộng đồng. & $55 / 60$ & 92 \\
\hline & R3 & Quản lý rừng bằng quy định của nhà nước. & $32 / 60$ & 53 \\
\hline
\end{tabular}

Kết quả khảo sát ở Vòng 1 cho thấy trong số 21 các giải pháp ứng phó với thiên tai và khí hậu cực đoan được các thành viên đưa ra, có 8 giải pháp có tỷ lệ lựa chọn dưới 70\%, các giải pháp phản ánh đúng với thực tiễn kinh tế - xã hội ở khụ vực. Thí dụ, giải pháp sử dụng giống cây trồng ngắn ngày người dân ít sử dụng vì phải bỏ tiền ra mua giống; giải pháp điều chỉnh thời vụ cây trồng khó áp dụng do điều kiện địa hình đồi núi, có nhiều tiểu vùng khí hậu vì thế người dân khó nắm bắt để điều chỉnh thời vụ trồng, chăm sóc và thu hoạch cây trồng.

Các giải pháp được lựa chọn ở Vòng 1 được chúng tôi chuyển thành các câu hỏi đóng cho Vòng 2, phân thành 5 lĩnh vực: (i) Lĩnh vực bảo vệ tính mạng và tài sản, có 4 giải pháp ký hiệu từ S1 đến S4; (ii) Lĩnh vực trồng trọt, có 6 giải pháp ký hiệu từ T1 đến T6; (iii) Lĩnh vực chăn nuôi có 5 giải pháp ký hiệu từ $\mathrm{C} 1$ đến $\mathrm{C} 5$; (iv) Lĩnh vực bảo vệ nguồn nước, có 3 giải pháp ký hiệu từ N1 
đến N5; (v) Lĩnh vực bảo vệ rừng, có 3 giải pháp ký hiệu là R1 đến R3.

Các chỉ số được sắp xếp theo thang điểm từ 1 đến 5 ( 1 = rất không đồng ý/không tác động, $2=$ không đồng ý/ít tác động, $3=$ đồng ý/tác động vừa, 4 = rất đồng ý/tác động mạnh, $5=$ hoàn toàn đồng ý/tác động nghiêm trọng). Kết quả tham vấn ở Vòng 2, được tổng hợp trong Hình 2, cho thấy:

1) Tri thức của cộng đồng trong bảo vệ tính mạng và tài sản: Chỉ số đánh giá của hai giải pháp $\mathrm{S} 1$ và $\mathrm{S} 2$ là khá cao, lần lượt là 3,83 và 4,35 . Hai giải pháp $S 3$ và $S 4$ có giá trị trung khá thấp lần lượt là 2,6 và $(2,28)$. Điều này phản ánh nhà ở của người dân tộc Thái, Lào được thiết kế hai tầng bằng gỗ (nhà sàn), tầng dưới làm kho lương thực và dụng cụ lao động, tầng trên dùng làm nơi sinh hoạt, tập quán ở nhà sàn đã giúp người dân đối phó với lũ ống, lũ quét. Cộng đồng dân tộc H'Mông, Dao, Hà Nhì cư trú phân tán ở núi cao, kiến trúc nhà với tường nhà dày từ 35 đến $40 \mathrm{~cm}$, được nhồi bằng đất, kỹ thuật và kiến trúc của ngôi nhà giúp cộng đồng đối phó hiệu quả với điều kiện khí hậu giá lạnh vùng núi cao, để chống tốc mái do giông lốc vào đầu mùa mưa cộng đồng thường dùng tre làm khung gia cố mái nhà. Các kỹ thuật nhà ở cho thấy cộng đồng hiểu rất rõ điều kiện khí hậu và lũ lụt, nên đã sử dụng các kỹ thuật phù hợp nhằm thích ứng với tự nhiên, điều này đã giúp người dân giảm thiểu được rủi ro thiên tai và khí hậu cực đoan.

2) Tri thức của cộng đồng trong lĩnh vực trồng trọt: Kết quả đánh giá cho thấy giải pháp $\mathrm{T} 1$ và $\mathrm{T} 6$ có giá trị trung bình thấp nhất, lần lượt là 2,3 và 2,5 , giải pháp có giá trị trung bình cao gồm T2 $(4,42)$, T3 $(4,05)$ và T4 $(3,95)$. Thực tế, trong cộng đồng trồng ngô, lạc luân canh với đất một vụ lúa, sử dụng cây rau đậu, cây bí và cây dưa mèo trồng xen với nương ngô và duy trì sử dụng một số giống cây trồng đặc sản địa phương để sản xuất. Đây là mô hình sản xuất điển hình của nông nghiệp bền vững ở vùng cao, bảo vệ đất và chống xói mòn, giữ được độ phì nhiêu của đất, đặc biệt giảm sâu bệnh cây trồng đảm bảo thu nhập cho người dân [4]. Do vậy, có thể khẳng định kỹ thuật luân canh, xen canh và trồng các giống đặc sản của người dân là một trong những giải pháp được các thành viên lựa chọn để đối phó hiệu quả với thiên tai và khí hậu cực đoan cho trồng trọt cây lương thực và thực phẩm.

3) Tri thức của cộng đồng trong lĩnh vực chăn nuôi nhằm ứng phó với rét đậm, rét hại cho đàn gia súc: Hai giải pháp $\mathrm{C} 1$ và $\mathrm{C} 4$ thấp nhất, lần lượt là 1,7 và 2,17 . Các giải pháp $\mathrm{C} 2, \mathrm{C} 3, \mathrm{C} 5$ có giá trị trung bình lần lượt là $3,66,3,58$ và 4,43 . Thực tế sản xuất cho thấy, đàn gia súc của người dân bị thiệt hại chủ yếu là do rét đậm, rét hại, do vậy người dân ưu tiên sử dụng các giải pháp $\mathrm{C} 2$, $\mathrm{C} 3, \mathrm{C} 5$ nhằm giải quyết vấn đề thức ăn và giữ ấm cho đàn gia súc trong điều kiện thời tiết rét đậm rét hại, giúp giảm thiểu rủi ro cho đàn gia súc.

4) Tri thức của cộng đồng trong quản lý nguồn nước: Giải pháp N3 có giá trị trung bình thấp $(2,3)$, hai giải pháp $\mathrm{N} 1$ và $\mathrm{N} 2$ có giá trị trung bình khá cao, lần lượt là 4,5 và 4,21 . Hai giải pháp có giá trị trung bình cao liên quan chặt chẽ với mô hình cộng đồng tự quản mà người dân đang duy trì. Các giải pháp người dân đang sử dụng dựa trên lợi ích chung của cộng đồng đã gắn kết các thành viên với tinh thần trách nhiệm cao trong quản lý, vận hành hệ thống thuỷ lợi, quản lý hiệu quả rừng đầu nguồn duy trì nguồn nước cho cộng đồng.

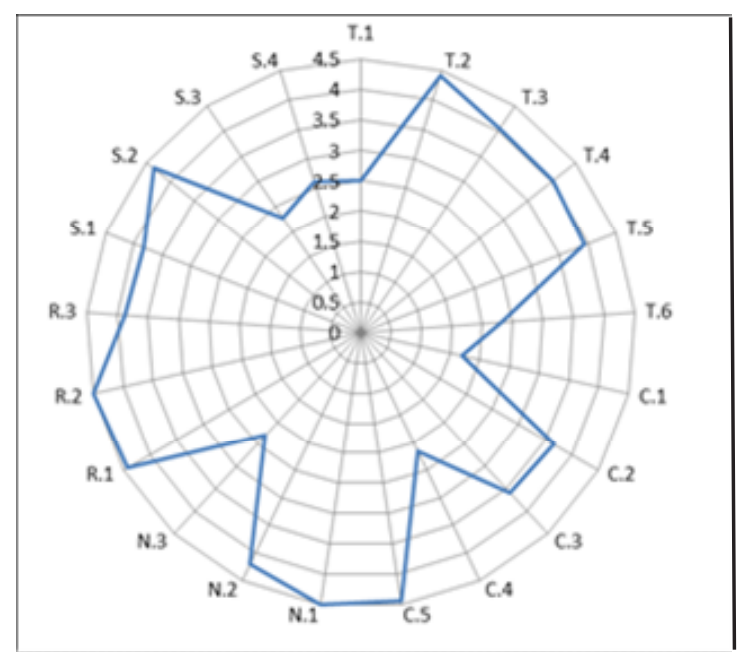

Hình 2. Kết quả khảo sát Vòng 2 về đánh giá hệ thống tri thức của cộng đồng dân tộc thiểu số tỉnh Lai Châu trong ứng phó với thiên tai và khi hậu cưc đoan 
5) Tri thức của cộng đồng trong quản lý tài nguyên rừng: Các giải pháp $R 1$ và $R 2$ có giá trị trung bình cao, lần lượt là 4,42 và 4,5 , giải pháp R3 có giá trị thấp $(2,9)$. Thực tế cho thấy cộng đồng vẫn đang duy trì phương thức trồng dược liệu, cây thực phẩm dưới tán rừng, hơn nữa, trong đời sống văn hóa cộng đồng vẫn duy trì hoạt động tín ngưỡng thờ rừng thiêng, quản lý chất lượng rừng bằng các giải pháp $\mathrm{R} 1, \mathrm{R} 2$, vì thế các giải pháp này được ưu tiên lựa chọn để duy trì sinh kế, tín ngưỡng trong cộng đồng.

Hệ số Kendall (W) được xác định với giá trị là 0,36 , cho thấy các giải pháp nhận được sự đồng thuận ở mức trung bình. Các giải pháp ứng phó với thiên tai và khí hậu cực đoan trong bảo vệ tính mạng và tài sản, trồng trọt, chăn nuôi, bảo vệ nguồn nước và bảo vệ rừng được lựa chọn bởi các thành viên tham gia là có mức độ tin cậy cao. Bởi, các thành viên tham gia đánh giá là những trưởng bản, người uy tín trong cộng đồng, cán bộ cán quản lý địa phương. Thực tế họ là những chuyên gia trong việc hình thành, thực hành áp dụng và phát triển các giải pháp được chọn lọc. Các đánh giá phản ánh sát thực đời sống kinh tế, văn hóa xã hội của cộng đồng các dân tộc thiểu số ở Lai Châu.

\section{Kết luận}

Nghiên cứu điều tra tri thức cộng đồng dân tộc thiểu số ở Lai Châu trong ứng phó với thiên tai và khí hậu cực đoan cho thấy: Thiên tai lũ ống, lũ quét, trượt lở đất đá, khô hạn và rét đậm rét hại là những nhân tố gây tác động lớn nhất đối với trồng trọt, chăn nuôi, nguồn nước, tài nguyên rừng và sức khỏe, tính mạng của cộng đồng dân tộc thiểu số ở Lai Châu. Để ứng phó với thiên tai và cực đoan khí hậu nhằm giảm thiểu tác động, đảm bảo an toàn tính mạng, tài sản và sản xuất, cộng đồng các dân tộc thiểu số ở Lai Châu đã sử dụng cây trồng bản địa có giá trị, duy trì kỹ thuật trồng luân canh, xen canh trên nương ngô và ruộng một vụ, tích trữ nguồn thức ăn và sử dụng phương pháp nuôi nhốt và thả rông đàn gia súc, sử dụng luật tục, tín ngưỡng để bảo vệ nguồn nước và tài nguyên rừng. Cộng đồng các dân tộc thiểu số ở Lai Châu đã hình thành và duy trì các mô hình truyền thống trong sản xuất nông nghiệp, chăn nuôi bền vững, tạo ra môi trường sống phù hợp, lành mạnh và hài hòa với thiên nhiên. Các tri thức này cần được đúc kết và nhân rộng và cần được lồng ghép vào các dự án, chính sách thích ứng với biến đổi khí hậu ở cấp cộng đồng.

\section{Tài liệu tham khảo}

1. Ban phòng chống và tìm kiếm cứu nạn thiên tai của tỉnh Lai Châu, Báo cáo tình hình thiệt hại do mưa lũ, thiên tai trên địa bàn tỉnh, các năm 2009, 2010, 2011, 2012, 2013, 2014, 2015, 2016.

2. Hoàng Xuân Tý và nnk (1998), Kiến thức bản địa của người vùng cao trong nông nghiệp và quản lý tài nguyên thiên nhiên; Các khái niệm và vai trò của tri thức bản địa. Nhà xuất bản Nông nghiệp Hà Nội.

3. Lê Đình Cúc (2007), Lai Châu và các dân tộc ở Lai Châu, Nhà xuất bản Văn hóa-Thông tin.

4. Lê Trọng Cúc (2016), Sinh Thái Nhân văn và phát triển bền vũng, Nhà xuất bản Đại học quốc gia Hà Nội.

5. Ủy Ban nhân tỉnh Lai Châu (2011), Quy hoạch sủ dụng đất tỉnh Lai Châu đến năm 2020.

6. Gregory J. Skulmoski, Francis T. Hartman and Jennifer Krahn (2007), The Delphi Method for Graduate Research Journal of Information Technology Education, Volume 6, 2007.

7. IPCC (2007), Climate Change: Impacts, Adaptation and Vulnerability.

8. UNESCO(2010), Indigenous knowledge and sustainability, http://www.unesco.org/ education/tlsf/mods/theme_c/mod11.html. 


\title{
INVESTIGATING AND CASTING THE KNOWLEDGE OF THE CO- MUNITY ETHNIC MINORITY IN LAI CHAU PROVINCE RESPONSE TO NATURAL DISASTER AND EXTREME CLIMATE
}

\author{
Vu Van Cuong', Tran Thuc ${ }^{2}$, Dinh Thai Hung ${ }^{3}$ \\ ${ }^{1}$ Department of Science and Technology of Lai Chau Province \\ ${ }^{2}$ Institute of Meteorology, Hydrology and Climate Change \\ ${ }^{3}$ Viet Nam Meteorological and Hydrological Administration
}

\begin{abstract}
The knowledge system of the ethnic minority community in Lai Chau Province has been accumulated over thousands of years in the process of production. These knowledge, which contains experience, practical techniques and behaviors with the natural environment, has helped people to mitigate the impact of natural disasters and climate extremes in cultivation, animal husbandry and natural resources management. This paper presents the results of knowledge assessment of ethnic minority communities in Lai Chau Province in response to natural disasters and climate extremes in the socio-economic activities. The Delphi method is applied in the sociological survey of the Dao people in Ho Thau commune, the H'Mong people in Ta Leng commune, the Ha Nhi people in Thu Lum commune of Muong Te district represent high ecological zones from 500m up to 1500m; The Lao community in Na Tam commune of Tam Duong district and Thai people in Tan Uyen represents a lowland ecological zone of $500 \mathrm{~m}$ or less. The valuable knowledge of ethnic minority communities in Lai Chau is analyzed and summarized in this study including: housing; methods of using local plant varieties in food production; techniques of intercropping cultivation, crop rotation on upland fields, one rice crop field; methods of shifting crops on upland fields; techniques in animal husbandry and management of water resources and forest resources with customary laws and beliefs.
\end{abstract}

Keywords: Knowledge of community, ethnic minorities, response to natural disasters and climate extremes. 